\title{
Fibre-Optic Sagnac Interferometer as Seismograph for Direct Monitoring of Rotational Events
}

\author{
Leszek R. Jaroszewicz ${ }^{1}$, Zbigniew Krajewski ${ }^{1}$ and Krzysztof P. Teisseyre ${ }^{2}$ \\ ${ }^{1}$ Military University of Technology \\ 2Institute of Geophysics Polish Academy of Sciences \\ Poland
}

\section{Introduction}

The possibility of a direct monitoring of rotational events has an important role in the seismological sciences as well as in the applied physics regarding large engineering structures.

According to the first aspect, a possibility of existence of the rotational phenomena in the seismic field has been discussed from the beginning of the earthquakes investigations. The interest in these phenomena has been stimulated by strange, rotary and even screw-like deformations that occur after earthquakes, often appearing on parts of tombs and monuments (Ferrari, 2006; Kozák 2006). The classical textbooks on seismology deny the possibility that the rotational phenomena, especially in form of seismic rotational waves SRW, could pass through a rock, so the earthquake rotational phenomena were explained by an interaction of standard seismic waves with a compound structure of objects they penetrate, which, in fact, might be the case (Teisseyre \& Kozak, 2003). Nevertheless, it was theoretically proved that even the SRW could propagate through grained rocks; later on, this possibility was extended on rocks with microstructure or defects (Eringen, 1999; Teisseyre \& Boratyński, 2002) or even without any internal structure (Teisseyre, 2005; Teisseyre et al., 2005; Teisseyre \& Górski, 2009), due to the asymmetric stresses in the medium. It should be noticed that the SRW were for the first time effectively recorded in Poland in 1976 (Droste \& Teisseyre, 1976). From this time, waves of this type have been studied in a few centers over the world. Taking into consideration large engineering structures, the rotational events monitoring is connected to the torsional effects in structures as well as to the interstory drift. Since the application of new materials and technologies for building constructions, they have irregular structures in-plane which causes difficulties in designing of the horizontal rotations of these structures especially during earthquakes (Schreiber et al., 2009). Recently in the above areas, the first monographs have been published (Teisseyre et al., 2006, 2008; Lee et al., 2009), covering the theoretical aspects of the rotation motion generation and propagation, as well as the examples of the field experiments.

A further experimental verification of the existing rotational phenomena in seismic events needs a new approach to the construction of the measuring devices, because the 
conventional seismometers are inertial sensors detecting only linear velocities. Similarly, the measurements of torsional response and interstory drift are reasonably easy on small scale models in a laboratory (Kao, 1998) but are much more difficult in real structures. The first of them can be measured by using a pair of accelerometers and then dividing differences in the horizontal accelerations by the distance between them in a direction perpendicular to the measured motion. Then this has to be integrated twice with respect to the time needed to give the torsional rotations (Schreiber et al., 2009). However, the inherent sensor drift and the small offset from zero in the absence of an input signals are the important limitations of this technique. According to the measurement of interstory drifts, it is, in principle, possible to arrange a frame from the floor below to near the ceiling above to set up the displacement transducers to measure the difference in displacements (McGinnis, 2004). However, again far from the hardware complexity of this approach, it is also vulnerable to building deformations.

For the above reason, the new instrumentations are important, especially those designed for an investigation of very small rotations. The near-field studies for the understanding of the mechanics of earthquakes is extensively reviewed by Kamamori (1994) and can be summarized as requirement for instruments with frequency range below $100 \mathrm{~Hz}$ and resolution in range of $10^{-6}-10^{-9} \mathrm{rad} / \mathrm{s} / \mathrm{Hz}^{1 / 2}$ for the SRW. Whereas the engineering strongmotion seismology needs devices operating in a frequency range of $0.05-100 \mathrm{~Hz}$ with resolution $10^{-1}-10^{-6} \mathrm{rad} / \mathrm{s} / \mathrm{Hz}^{1 / 2}$ (Cowsik et al., 2009).

Since the Sagnac effect (Sagnac, 1913) measures the rotation directly, an application of the sensor based on this effect seems to be ideal for the construction of the rotational seismometer - RS. Its greatest strength is the fact that it does measure absolute rotations or oscillations, so that it does not require any external reference frame for its measurement. This means that it measures true rotations even during an earthquake, where nothing remains static. Since it is an entirely optical device, it does not have the problems that characterize inertial mass transducers, also. We distinguish two systems based on the Sagnac interferometer: a ring laser rotational seismometer - RLRS (Schreiber et al., 2001), and a fibre-optic rotational seismometer - FORS (Takeo et al., 2002; Franco-Anaya et al., 2008; Schreiber et al., 2009). The first of them is a stationary system constructed for investigation disturbances in the Earth rotation, whereas the second one based on the application commercially available fibre-optic gyroscope - FOG.

Even though 40-ty years of the FOG investigation gives very precise systems useful for different areas including inertial navigation, their constructions are optimized for the detection of angular changes rather than rotation speed, then may generate the same difficulties during the investigation rotational phenomena. For the above reason in this chapter we conclude ours experiments connected to another approach to the rotation phenomena investigation (Jaroszewicz et al., 2003). We started the second part with a short description of the Sagnac effect with the same historical review of its application as FOG. In part 3, which is the main part of this chapter, we described the Autonomous Fibre-Optic Rotational Seismograph - AFORS, with its optical part based on the FOG construction, whereas the special autonomous signal processing unit - ASPU optimizes its operation for the measurement of rotation speed instead of angular changes. Finally, in part 4 we presented the same results obtained during the application of these systems for the rotational events investigation as well as a monitoring of building torsional moves. 


\section{Sagnac effect and its application as FOG}

Sagnac (1913) first demonstared the feasibility of an optical experiment capable of indicating the state of rotation of the frame of reference in which his interferometer was at rest. The basic principle of Sagnac's interferometer is given in Fig. 1a. The input light beam is split by a beam spliter into a beam circulating in the loop in a clockwise - cw direction and a beam circulating in the same loop in a counterclockwise - ccw direction. The two beams are reunited at a beam splier so that interference fringes are observed in the output light. When the whole interferometer with a light source and the fringe detector is set in rotation with an angular rate of $\Omega \mathrm{rad} / \mathrm{s}$, a fringe shift $\Delta \mathrm{Z}$ with respect to the fringe position for stationary interferometer is observed, which is given by the formula:

$$
\Delta \mathrm{Z}=\boldsymbol{\Omega} \cdot \mathbf{A} / \lambda_{0} \mathrm{C},
$$

in which $\mathbf{A}$ is the area enclosed by the light path. The vacuum wavelength is $\lambda_{0}$ and the freespace velocity of light is $c$. The scalar product $\Omega \cdot \mathbf{A}$ denotes that $\Delta Z$ is proportional to the cosine of angle between the axis of rotation and the normal to the optical circuit. Sagnac also established that the effect does not depend on the shape of the loop or the center of rotation.

(a)

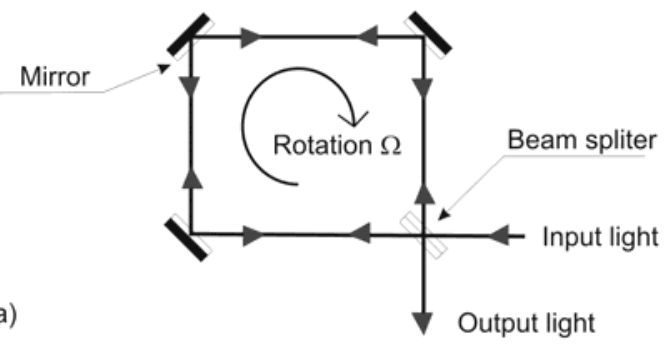

(b)

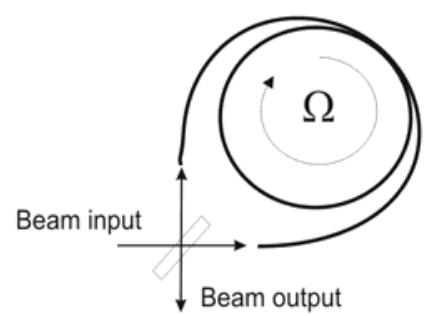

Fig. 1. Schematic of Sagnac's interferometer (a) and its implementation in fibre optic technique (b)

It should be noticed that a German graduate student, Harress (1912), performed a very similar experiment for a thesis project a few years before Sagnac did his experiment. Harress used an optical circuit which consisted of a ring of total reflecting prism, but his objective was quite different from Sagnac's. According to Sagnac's data (Sagnac, 1914), for the wavelength of indigo mercury light and a loop area $A=866 \mathrm{~cm}^{2}$, a fringe shift of 0.07 fringes was clearly detectable for the rate of rotation of $2 \mathrm{rps}$. However, according to the other data (Post, 1967) the fringe shift detectability at that time was probably of an order of 0.01 of a fringe, so precision of the Sagnac's experiment therefore may have been close to marginal.

A Sagnac experiment of great precision was subsequently performed by Pogany (1926). With a loop area $A=1178 \mathrm{~cm}^{2}, \Omega=157.43 \mathrm{rad} / \mathrm{s}$, and $\lambda_{0}=546 \mathrm{~nm}$, he reproduced within $2 \%$ the theoretically expected fringe shift $\Delta Z=0.906$. Michelson and Gale (1925) succeeded in demonstrating the rotation of the Earth by means of the Sagnac effect, also. To obtain the required sensitivity they had to choose an unusually large size (rectangular $0.4 \times 0.2$ mile) for the surface area enclosed by the beam. Summarizing, the experiments of Sagnac, Pogany, and Michelson-Gale and the results of Harress, as reinterpreted by Harzer (1914), the following features of the Sagnac effect according to the fringe shift can be given (Post, 1967): 


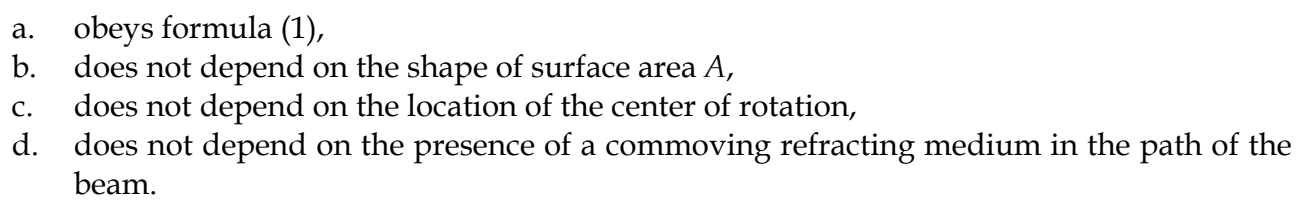

The fibre-optic version of the Sagnac interferometer uses a long length optical fibre $L$ coiled in a loop of diameter $D$, as it is shown in Fig. 1 b (Vali \& Shorthil, 1976). In this approach, instead of the fringe shift $\Delta Z$, a phase shift $\Delta \phi$ is produced between $\mathrm{cw}$ and $\mathrm{ccw}$ propagating light, given by

$$
\Delta \phi=\frac{2 \pi L D}{\lambda_{0} c_{0}} \Omega
$$

where $\Omega$ is the rotation component in the axis perpendicular to the fibre-optic loop. In other words, the sensitivity of the Sagnac interferometer in this approach is enhanced not only by increasing the physical sensor loop diameter but also by increasing the totals length of the used fibre. It is easy to see that three such interferometer with loops plane in perpendicular directions give information about a space vector of the rotation rate. This data after an integration in time domain shows the position changes in space - and it is idea of the optical gyroscope.

35-years after the above date its technical application as the FOG is the best recognized interferometric sensor made in the fibre-optic technology. However, because its useful signal is the angular changes, the detected phase shift $\Delta \phi$ is integrated in time needed to give it. Moreover, for a desired rotation rate in the range of $10^{-6}-10^{-9} \mathrm{rad} / \mathrm{s}$ the Sagnac effect generates a very small phase shift, so needs to be separated from other disturbances and protected so that the Sagnac effect is the unique nonreciprocal effect in the device. For the above reason all FOG uses shown in Fig. 2 the reciprocal configuration (Urlich, 1980) also called the minimum configuration (Arditty \& Lefevre, 1981) where a perfect balance between both counter-propagating paths is obtained simply with a truly single-mode (single spatial mode and single polarization) filter at the common input-output port of the interferometer, even if the propagation is not single-mode along the rest of the interferometer.

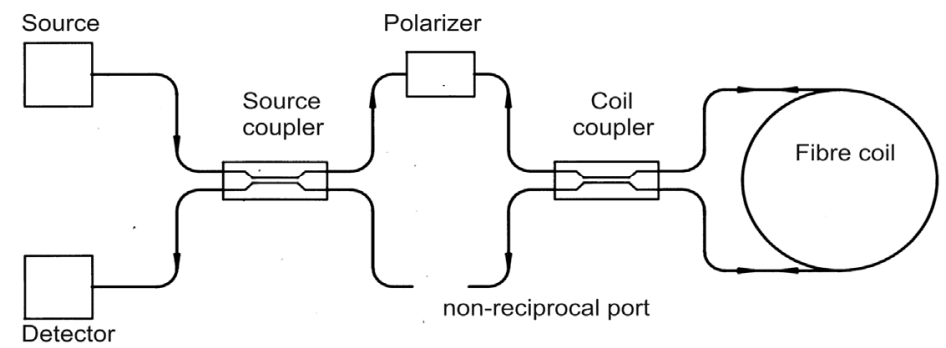

Fig. 2. The minimum configuration of the FOG

The FOG interferometer using the minimum reciprocal configuration yields a raised cosine response as any interferometer. It is classical to bias such an even response that has a maximum at zero by modulating the abscissa parameter and demodulating the output 
signal, which yields an odd response. The FOG uses a reciprocal phase modulator - PM at the end of the coil, which yields, because of the propagation delay, as a modulation of the phase difference without any residual zero offset (Martin \& Winkler, 1978). This was a very important step in the progress of performance, but it was not enough for an ultimate performance which is obtained only if the unbiased response is perfectly even and the biasing modulation has only odd frequencies. For the above reason, the PM being actually a delay line filter, the operation at the so-called proper or eigen frequency (Bergh et al., 1981) - the delay through the coil is half the period of modulation, suppresses the residual even harmonics which are always present because of spurious nonlinearities of the modulation chain. Today the FOG system using also a broadband source has the intensity statistics that happens to cancel the Kerr effect induced phase difference in a Sagnac interferometer (Ezekiel et al., 1982). Such a broadband source is also needed, as it is well-known today, to remove coherence related noise and drift due to backscattering and backreflection as well as lack of rejection of the polarizer (Fredricks \& Ulrich, 1984; Lefèvre et al., 1985a; Burns, 1986). Finally, for achieved the high scale factor linearization, FOG utilizes a digital phase step feedback (Lefèvre et al., 1985b) using the same reciprocal PM as the biasing modulation and an all-digital processing scheme where the gyro modulated signal is sampled with an AD convertor and the demodulation performed by digital subtraction (Auch, 1986; Arditty et al., 1989).

Since all-digital processing scheme implemented in the current FOG system is optimized for the presentation of angular changes rather than rotation rate, the same problems exist for its optimized application for measurement of the last phenomena which are interesting for the rotational seismology. For the above reason in the next part of this chapter we have described our experiments in development of the fibre-optic rotational seismograph system. Its construction is based on experiences according to the FOG development described above, but the system is optimized for a direct measurement of the rotation rate only (Jaroszewicz et al., 2003). Such an approach gives a system which through a direct use of the Sagnac effect can limit drift influence on a device operation. Moreover, the special construction of a signal processing unit protects easily its monitoring via Internet including data collecting and managing as well as device remote control.

\section{Autonomous Fibre-Optic Rotational Seismograph}

A detailed description of the AFORS system was published previously (Jaroszewicz at al., 2011a, 2011b) hence here we summarized the above data regarding its construction, calibration and management. Now we present two examples of these devices - AFORS-1 located in the Książ (Poland) seismological laboratory for the investigation of the rotational events connected to earthquakes, and AFORS-2 located in Warsaw (Poland) used for initial works connected to the investigation of the irregular engineering construction torsional response and the interstory drift (Jaroszewicz et al., 2011c). Before the end of 2011 the next system AFORS-3 will be available as the replacement to the older version FORS-II mounted in the Ojców (Poland) seismological laboratory (Jaroszewicz \& Krajewski, 2008).

The optical head of the constructed AFORS devices uses a fibre interferometer in a minimum optical gyro configuration (Jaroszewicz et al. 2006a), as it is shown in the upper part of Fig. 3a.

The application of the broadband low coherence superluminescent diode - SLD (EXALOS Switzerland with optical power $-20.87 \mathrm{~mW}$, operation wavelength $-1326.9 \mathrm{~nm}$, and spectral radiation band $-31.2 \mathrm{~nm}$,) gives possibility for a minimisation of polarization influence on 


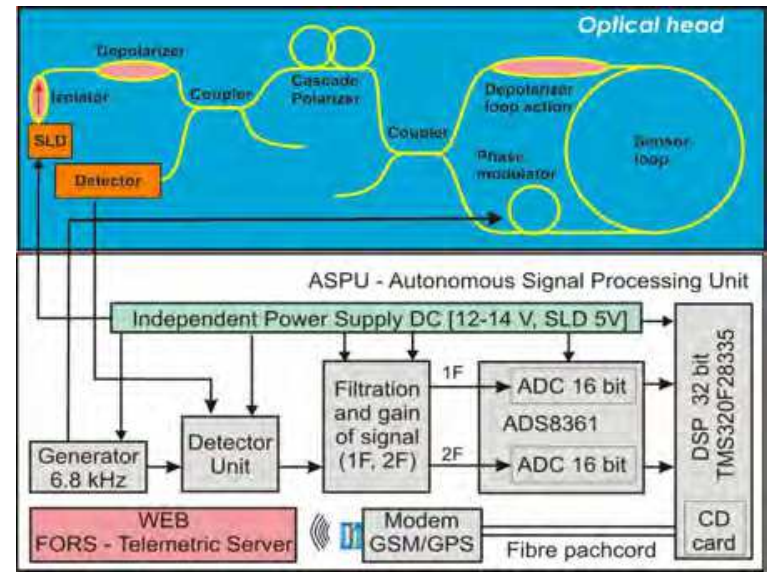

(a)

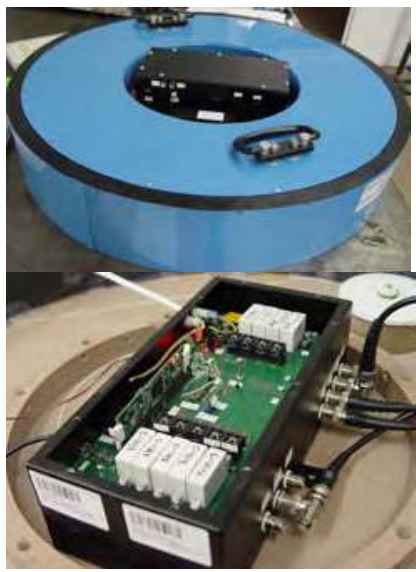

(b)

Fig. 3. General schema of the AFORS (a): upper - the optical head (generation of the Sagnac phase shift proportional to measured rotation rate $\Omega$ ), bottom - Autonomous Signal Processing Unit (rotation calculation and recording), (b): general view of all AFORS (top) and ASPU (bottom)

the system operation by achieving light depolarization in a sensor loop (Krajewski et al., 2005). Next the set of cascade fibre polarizers (with total extinction above $100 \mathrm{~dB}$ ) enables a true single mode operation of the whole system and guarantees that the only nonreciprocal effect in system is the Sagnac effect. Moreover, a $0.63 \mathrm{~m}$ diameter sensor loop has been made from a special composite material with permalloy particles for shielding from the magnetic field. A long length of SMF-28 fibre has been winded in a double-quadrupole mode (Dai et al., 2002) with a $0.2 \mathrm{~mm}$ Teflon insulation between each fibre layers which is for the thermal stabilization of the sensor's work, for expected 2-4 degree per day temperature fluctuation in seismic observatories. The system optimization made for AFORSs (15000 m length of fibre with attenuation equal to $0.436 \mathrm{~dB} / \mathrm{km}$ in sensor loop for AFORS-1 and respectively, 15056 $\mathrm{m}$ and $0.450 \mathrm{~dB} / \mathrm{km}$ for AFORS-2) allows for theoretical sensitivity in quantum noise limit (Jaroszewicz \& Wiszniowski, 2008) equal to $1.97 \cdot 10^{-9} \mathrm{rad} / \mathrm{s} / \mathrm{Hz}^{1 / 2}$ and $2.46 \cdot 10^{-9} \mathrm{rad} / \mathrm{s} / \mathrm{Hz}^{1 / 2}$, respectively for AFORS-1 and AFORS-2. The above mentioned difference between two constructed devices is connected to their total optical loss which is equal to $13.33 \mathrm{~dB}$ and 14.47, respectively for AFORS-1 and AFORS-2 (Jaroszewicz et al., 2011b).

The optimisation for a detection of rotation rate is made on the basis of special detection units and utilizes a synchronous detection with properly chosen PM that operates according to the principles presented in part 2 (Krajewski, 2005). For AFORS, a new Autonomous Signal Processing Unit - ASPU (ELPROMA Ltd), according to the scheme shown in the lower part of Fig. 1a, has been developped. The ASPU enables the detection of a rotation rate $\Omega$ from proper selection (special low-pass filters) and processing (in digital form) the first $A_{1_{\omega}}$ and the second $A_{2 \omega}$ amplitude of the harmonic output signal, on the basis of the following relation (Jaroszewicz et al., 2011a):

$$
\Omega=S_{o} \arctan \left[S_{e} \cdot u(t)\right] ; \quad S_{0}=(\lambda \bullet c) /(2 \bullet \pi \bullet L \bullet D), \quad u(t)=\mathrm{A}_{1 \omega} / \mathrm{A}_{2 \omega}
$$


where: $S_{o}$ - optical and $S_{e}$ - electronic constants, related to the parameters of used optical and electronic components. The digital form of a signal processing enables the application of the 32-bit signal processor TMS320F283535 (Texas Instruments) working with a frequency of $150 \mathrm{MHz}$ as an optimal DSP unit, for a calculation and monitoring of the rotation rate $\Omega$ on the basis of signal frames having 1024 length of 16-bit samples. Finally, the obtained results are stored on a CD card and transmitted by a GSM/GPS module to a special WEB FORS Telemetric Server.

The evaluation of the optical and electronic constans needs a sensor calibration process, which is based on the measurement of the Earth rotation for Warsaw, Poland i.e. $\Omega_{\mathrm{E}}=9.18$ $\mathrm{deg} / \mathrm{h} \equiv 4.45 \cdot 10^{-5} \mathrm{rad} / \mathrm{s}$ (Krajewski et al., 2005; Jaroszewicz et al., 2011a). During the calibration the AFORS is mounted vertically on a rotation table. For the sensor loop directed in the East-West direction, the measured rotation equals zero because in this direction, its plane is collinear with the Earth rotation axis, whereas for the North-South direction, the measured signal obtains the maximum plus or minus values because the plane of a sensor loop is perpendicular to the vector component of the Earth rotation $\Omega_{\mathrm{E}}$. For two existing systems we obtained the following values for the above constants: $S_{0}=0.0043 \mathrm{~s}^{-1}, S_{e}=0.0144$ for AFORS- 1 and $S_{0}=0.059 \mathrm{~s}^{-1}, S_{e}=0.0134$ for AFORS- 2 .

After the practical construction of the AFORS devices, their accuracy has been checked. However, this work made in MUT located in Warsaw city, could give limited information on the system accuracy because of urban noises. Figure 4 summarizes these measurements. Since the ASPU allows for step changes of the detection frequency band in the range from $0.83 \mathrm{~Hz}$ to $106.15 \mathrm{~Hz}$ (Jaroszewicz et al., 2011b), the obtained accuracy is at the level of $5.07 \cdot 10^{-9} / 4.81 \cdot 10^{-9} \mathrm{rad} / \mathrm{s}-5,51 \cdot 10^{-8} / 6.11 \cdot 10^{-8} \mathrm{rad} / \mathrm{s}$ (for AFORS-1/AFORS-2), respectively for the lower and higher working frequency band. As one can see, the obtained values are well correlated with $\Omega_{\min }$ in quantum noise limitation. It should be noticed that the linear dependence of AFORS sensitivity and accuracy in the detection frequency range is the advantage of this system, taking into account the expected frequency characteristics of the rotational seismic waves (Teisseyre et al., 2006). For comparison, Fig. 4 includes also the measured accuracy of the older system FORS-II; which was 4.3.10-8 rad/s (Jaroszewicz et al., 2006; Jaroszewicz \& Krajewski, 2008), at $20 \mathrm{~Hz}$ - the fixed detection frequency band.

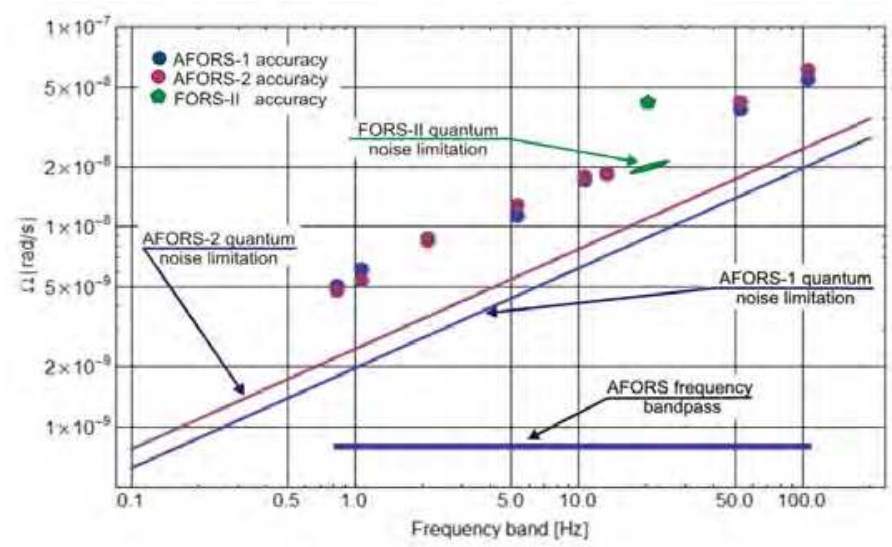

Fig. 4. The accuracy measured in Warsaw, Poland for the chosen detection band for three devices: AFORS-1, AFORS-2 and FORS-II 
A FORS-Telemetric Server with its main page shown in Fig. 5a (reader can use http:/ / fors.m2s.pl with login and password - AFORSbook for free access to the system) is used for data storing and for monitoring the work of the FORS-II and the AFORSs. Because ASPU of the AFORS contains a GSM/GPS module and an independent power supply for all electronic components of the system, hence the AFORS is fully autonomous and mobile system. In this moment, the 3 devices are managed via server: FORS-II, AFORS-1, AFORS-2 located in Ojców, Książ and Warsaw (all in Poland), respectively (Jaroszewicz et al., 2011b) as it is shown in Fig. $5 b$.

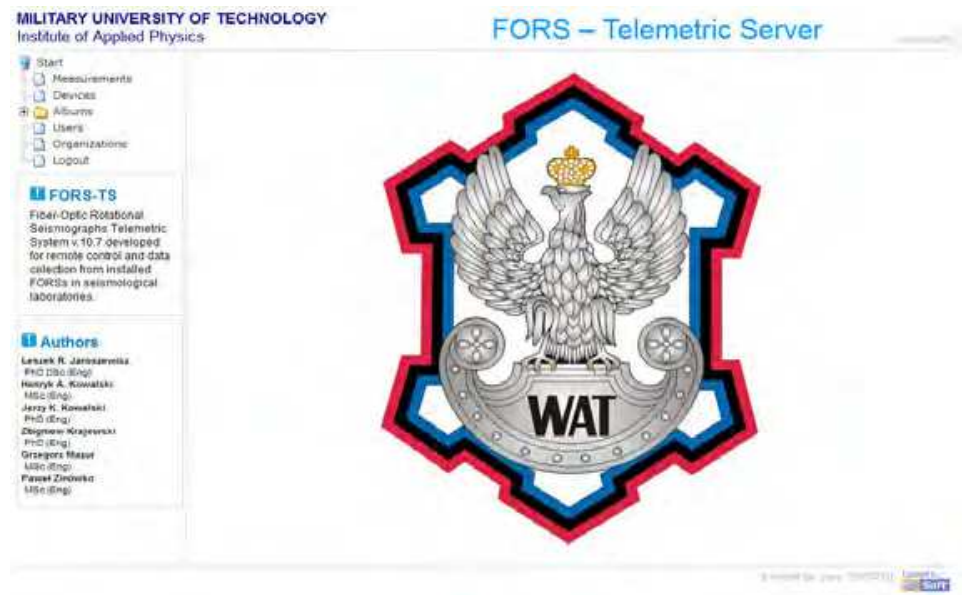

(a)

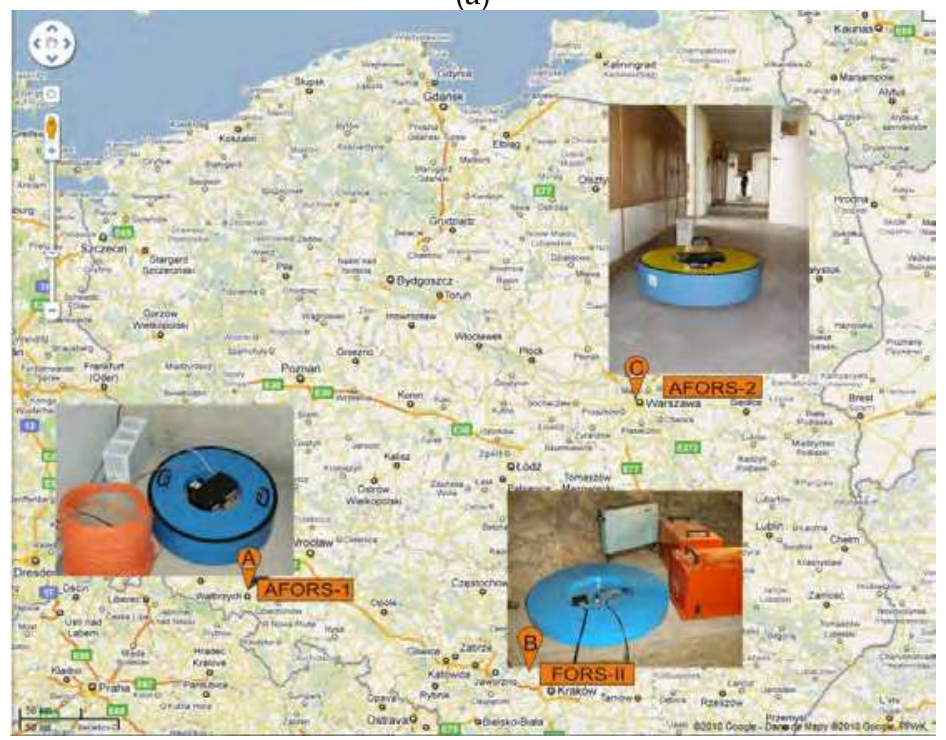

(b)

Fig. 5. Elements of WEB page for AFORS managing: (a) the main page of FORS - Telemetric Server, (b) the GOOGLE map with devices localization 
The applied technology gives possibility for the remote (via Internet) controlling and changing of all electronic parameters of the ASPU for a given sensor made according to the AFORS technology, as presents, for example, the bookmark Config for the AFORS-1 in Fig. 6a. This remote control may comprise a software upgrade. Moreover, the bookmark DataEVariables (Fig. 6b) monitors, for given AFORS, in real time the main data and variables with possibility for the remote changing of the threshold - the level of signals which initialize automatic data storing and its GSM transfer. Additionally, the top right corner of bookmarks for the given system on server contains the information on a current date and time and the four main AFORS's parts of state of work (good - as green, partially good as

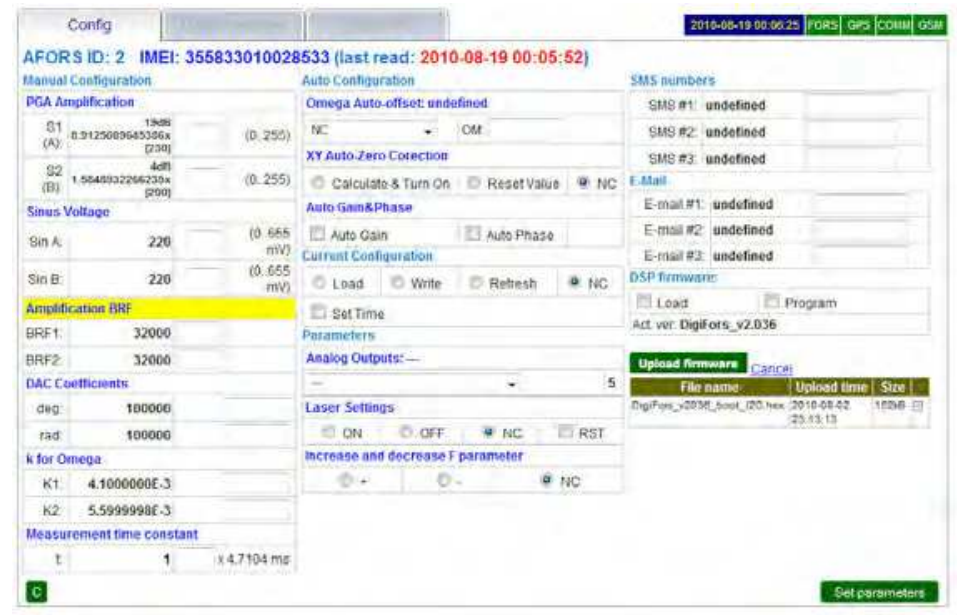

(a)

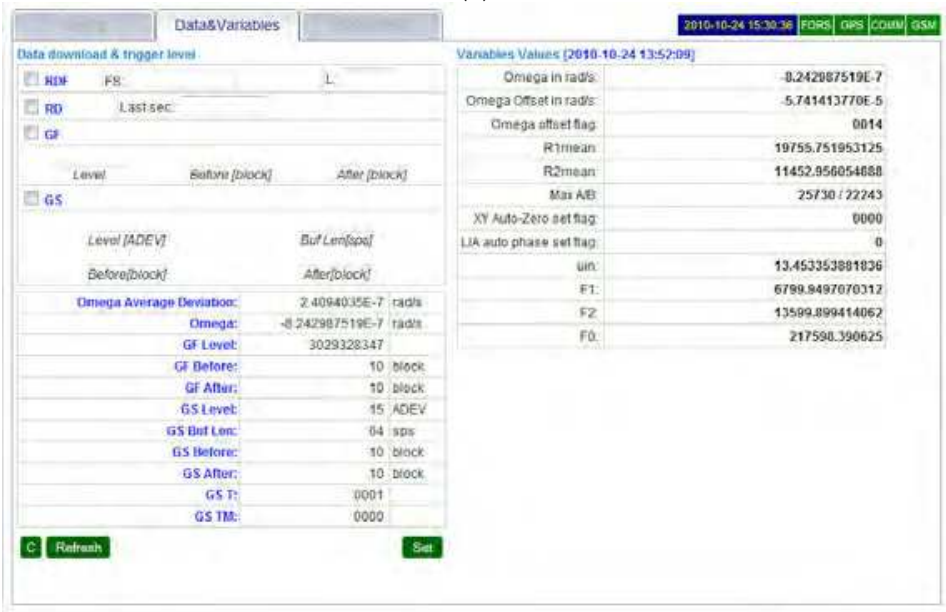

(b)

Fig. 6. The view of two main bookmarks for AFORS-1at the FORS - Telemetric Server: (a) Config, and (b) DataEVariables 
yellow or no work - as black, respectively). The bookmark GSM/GPS (not shown in figure, see for example Jaroszewicz et al., 2011a) monitors in real time the GSM parameters as well as the GPS parameters which include the AFORSes' global localization (see Fig. 5b). Yet another bookmark named Measurement presents the collection of data recorded by different devices connected to the server. These data are stored with the main parameters of AFORS in the recording time: ADEV - rotation rate average deviation in rad/s, Omega Offset rotation rate offset in rad/s, GS Level/Before/After - adjusted level of signal for data stored, and $\triangle \mathrm{B}$ - adjusted detection band. In this way, in our opinion, the AFORSes with their management via FORS - Telemetric Server are fully adopted for monitoring of rotational phenomena connected to earthquakes as well as torsional response and interstory drift of the irregular structures in-plane existing during any ground moves.

\section{Examples of the experimental data obtained by AFORS}

The previously obtained data from an older system FORS-II have been wide discussed as well as summarized (Jaroszewicz et al., 2006, 2008). For the above reason here we present the summarized data obtained with regard to the AFORS application where AFORS-1 is installed in the Książ (Poland) seismological laboratory for the recording of the rotational phenomena connected to earthquakes, whereas AFORS-2 has been used in the initial experiments for monitoring building rotational moving.

The main source of disturbance during an investigation by AFORS-2 of a building rotation moving was an urban ground motion generated by tram moves within a $50 \mathrm{~m}$ distance from a building wall parallel to it. The investigated building is a light construction (five floors of aluminium structure with sandwich walls and ceilings), and the AFORS-2 has been installed, subsequently on the second and first floors in the hall, in the same vertical position (with accuracy of about $10 \mathrm{~cm}$ ). Since it is an old building with asbestos used as an inner wall isolation, now it is not in use by the academy anymore, so we expected that the recorder signals will be connected to an external perturbation. Figure 7 presents the building moves recorded on the first and the second floors (difference about $3 \mathrm{~m}$ of height) for relatively the same ground motion generated by tram moves nearly by midnight on July 13th (AFORS-2 on the first floor) and July 14th (AFORS-2 on the second floor). Since it was a middle of the night during summer holidays, the academy area was empty which had a direct influence on recorded signals and they were very clear. As one can see in the above

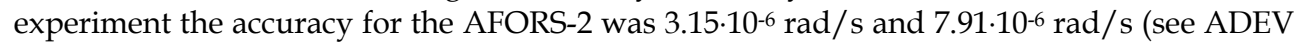
parameter in the left down corner of two pictures in Fig. 7), for the chosen detection band equal to $21.23 \mathrm{~Hz}$. The amplitude of the detected rotation rate was about twice higher for the second floor, and was much higher than the system accuracy (more than ten orders).

The urban noise influence on the recorded signals can be observed on the data presented in Fig. 8, which have been obtained in the morning when the Academy opened for work. As one can see the higher amplitude as well as frequency were observed in this time. However, again the much higher amplitude of torsional moves of the building is observed on the higher floor of building.

The above initial results show that the device type AFORS can be useful for a continuous monitoring of an engineering structure of, for example, multi-storey buildings with regard to the investigation of their torsional rotations as well as measuring interstory drifts. These measurements are made without any reference frame which is very important during earthquakes and may be made only by a system based on the Sagnac effect. In comparison 
to the commercially available FOG instruments such as $\mu$ FORS-1, the proposed system is designed for a direct measurement of a rotational rate, whereas any FOG measures change the angle which is written in their inner electronic system and difficult to direct changes. Additionally, our system prepared according to the AFORS technology has developed the software designed for the Internet system monitoring as well as the remote control which can manage a large numbers of such devices in a useful way for the operator.
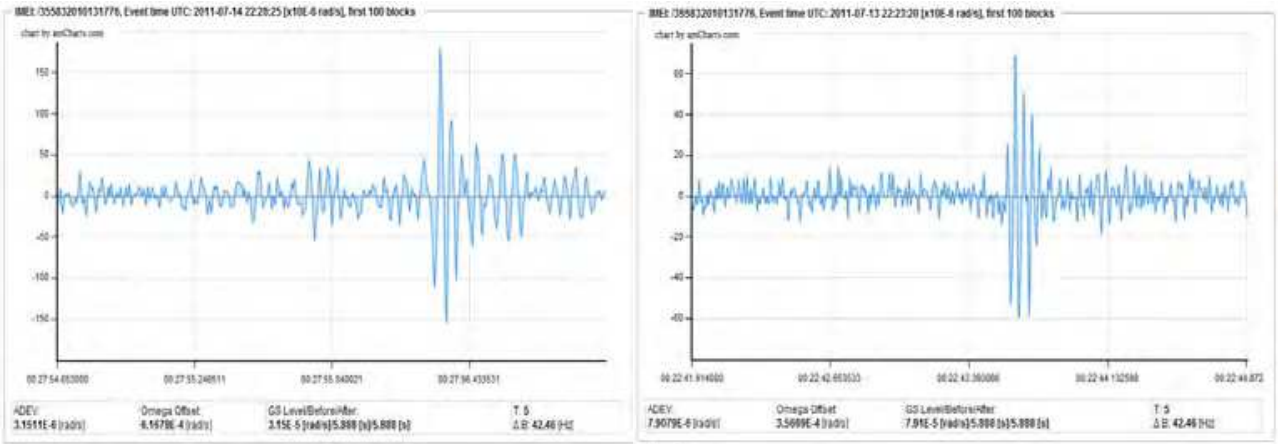

Fig. 7. The data recorded on second (left) and first (right) floor as response for ground moves after tram pass through street
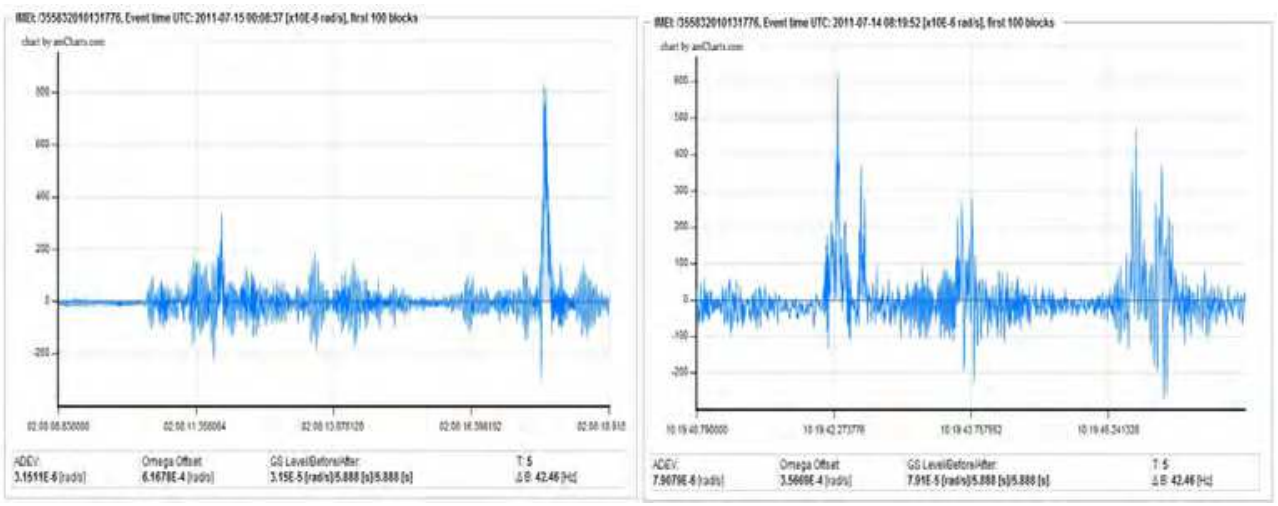

Fig. 8. The data recorded on the second (left) and the first (right) floor as a response for the ground moves generated by the street morning intensity within a distance of about $50 \mathrm{~m}$ from and parallel to the long building wall

At beginning of July, 2010 the AFORS-1 has been installed in the Książ (Poland) seismological observatory together with a set of the Two Antiparallel Pendulum Seismometers (TAPS-1 and TAPS-2) constructed by the Institute of Geophysics (Teisseyre et al., 2003). As usually, TAPSes are placed perpendicularly, in directions N-S and E-W.

As the first example we repeat here (Fig. 9) the histogram of the previously analyzed data (Jaroszewicz et al., 2011b) collected in Książ on March 11th, 2011 at 6 h 58 min. (after Honshu earthquake, M=9.0 on 11 March 2011 at 5 h 46 min. 23 s, recorded in Książ on 11 March 2011 at 5 h $58 \mathrm{~min} .35$ s.). The above data were obtained from the common for AFORS 


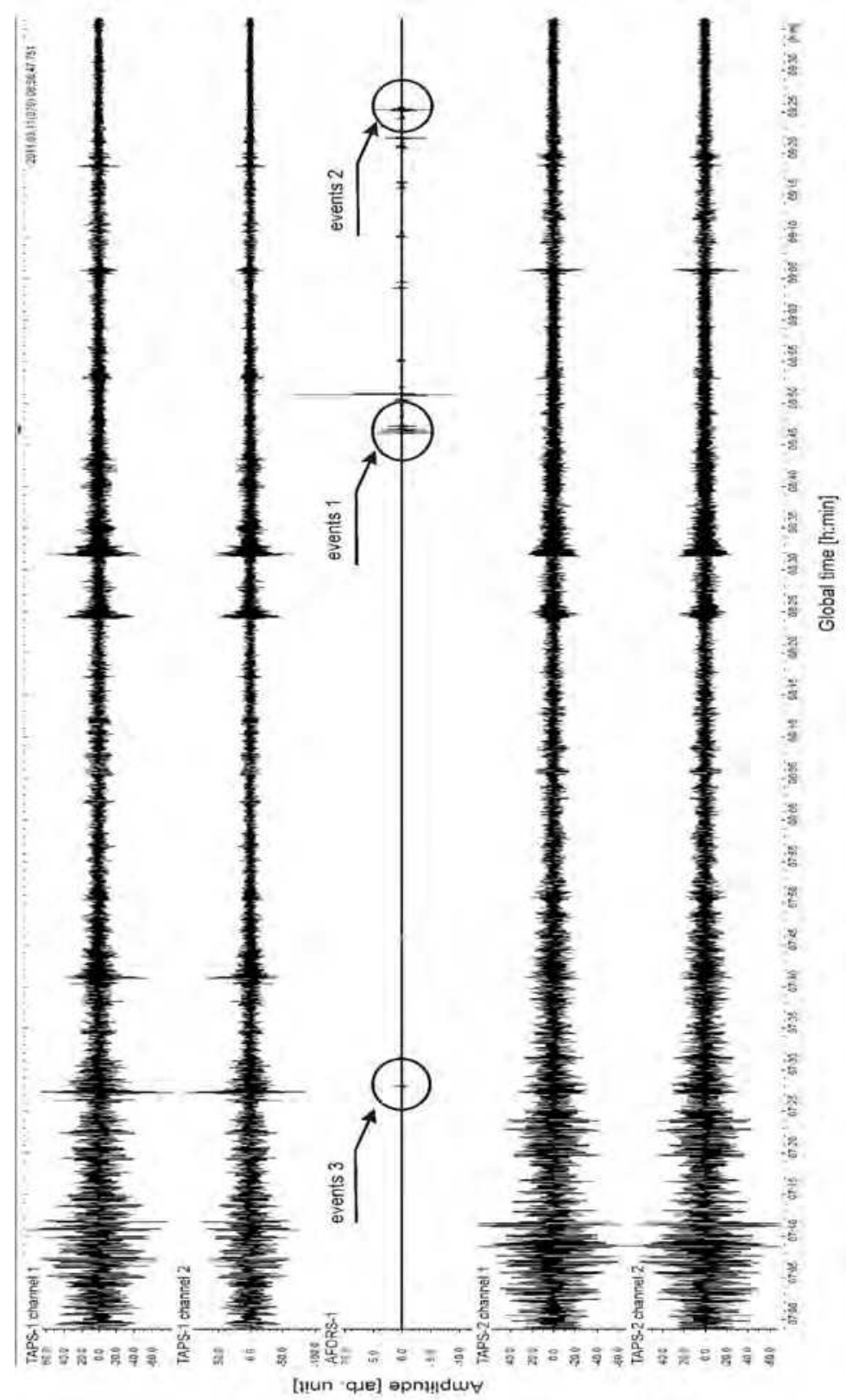

Fig. 9. The plots of the seismic events recorded in Książ on March 11th, 2011, starting from 6 h 58 min, after the Honshu M=9.0 earthquake, all times UTC (Jaroszewicz et al., 2011b)

and TAPSes standard seismic recording system named KSPROT with the samples of a signal with the frequency $12.8 \mathrm{kHz}$ and after re-sampling stores with the frequency $100 \mathrm{~Hz}$. 
It should be noticed that in the previously paper (Jaroszewicz et al., 2006), we used a wrong name for this station, KST. We underline that here only the AFORS-1 shows the rotational component in a direct way (plots marked as AFORS-1). The rotational component is obtained also from the TAPS system, calculated from the recordings of linear motions in four channels (data named TAPS-1 channel 1, TAPS-1 channel 2, TAPS-2 channel 1 and TAPS-2 Channel 2) with the application of a suitable mathematical procedure, which has been widely described in the previous paper (Solarz et al., 2004). Since AFORS records rotation in a direct way, we use this recording as the reference source, despite that the rotations calculated from TAPSes are generally poorly correlated with it. In the results presented in Fig. 9, a good correlation has been found mainly in short bursts of seismic oscillations, marked here as "events 3", "events 1 " and "events 2". These were clusters of short peaks, found when the traces of the great Honshu Earthquake were studied (without much success in the domain of rotational field component, but this is not strange concerning the distance to the earthquake focus and the characteristics of our instruments). After the preliminary analysis, from each group only one event was chosen, and these we call event 3 , event 1 and event 2 accordingly.

For event 1, the data from AFORS-1 were identified by the FORS-Telemetric Server (see Fig. 10a) as the rotational event of an amplitude of about $15^{\cdot 10^{-6}} \mathrm{rad} / \mathrm{s}$ with AFORS- 1 accuracy equal to $4 \cdot 10^{-8} \mathrm{rad} / \mathrm{s}$ for the given frequency bandpass which was about $10.6 \mathrm{~Hz}$. The rotation calculated from the linear motions recorded in TAPS system has similar characteristic, as is seen in Fig. 10b (with arbitrary units of amplitude). Nevertheless, we observed some time advance in a relation to the AFORS-1 registration as well as apparent disturbances, visible before and after the event; these may result from a limited accuracy of TAPSes as was previously mentioned (Jaroszewicz \& Krajewski, 2008).
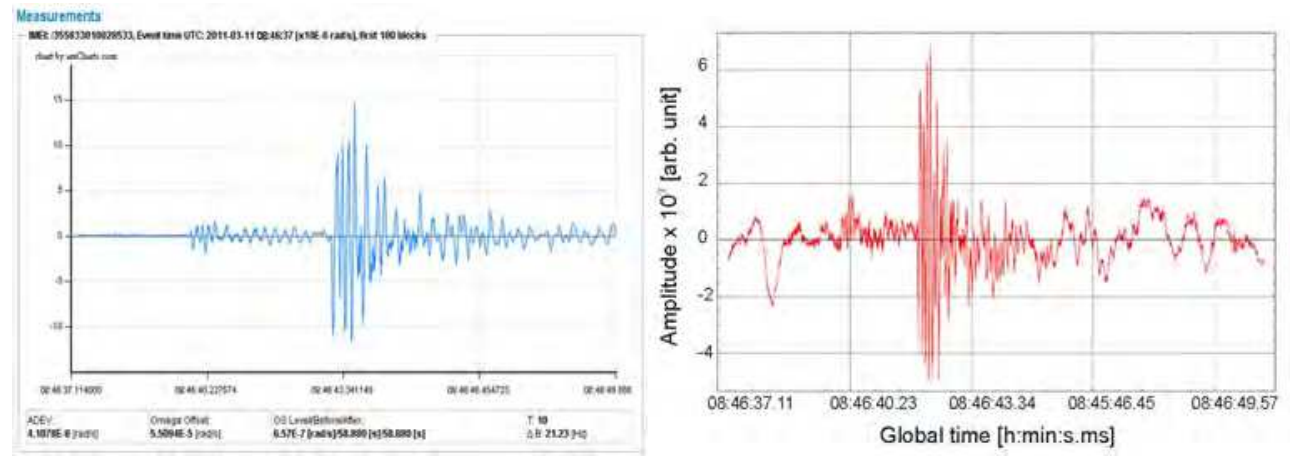

Fig. 10. The rotational event 1 from Fig. 5 on 11 March 2011 - a): recorded from AFORS-1 in the FORS -Telemetric Server at 8 h $46 \mathrm{~min}$; - b): calculated from TAPSes four channels (Jaroszewicz et al., 2011b)

For further study, the recordings of several mining shocks have been chosen; these shocks occurred in the Legnica-Głogów Copper Mining District - LGOM in Western Poland. Some typical results of the analysis of strong shocks are presented here; for the event which occurred in April 30th at 03:32 UTC - the magnitude 2.9 had been found, for the event from June 28th, 23:16 UTC - magnitude 3.2. For viewing the data, for the normalization of the sampling to the first channel and for writing selected time-periods as ASCII, we used the 
programs written by dr Jan Wiszniowski of the Institute of Geophysics, P.A.Sci. Subsequent analysis was done in Matlab®.

The rotational motions in the trace of a seismic event, recorded from AFORS- 1 and indirectly obtained from TAPSes, differ substantially, as it is seen in Fig. 11. The signal obtained from AFORS-1, here - the middle plot, has much more peaks and indentations than both the channel 1 and channel 4, which are two of the four channels of the TAPSes system. The signals from TAPSes are shown in $\mu \mathrm{m} / \mathrm{s}$, while the rotational signal from AFORS-1 is in conventional units. In the following Figures, the rotations found from TAPSes system are plotted in $\mathrm{rad} / \mathrm{s}$.

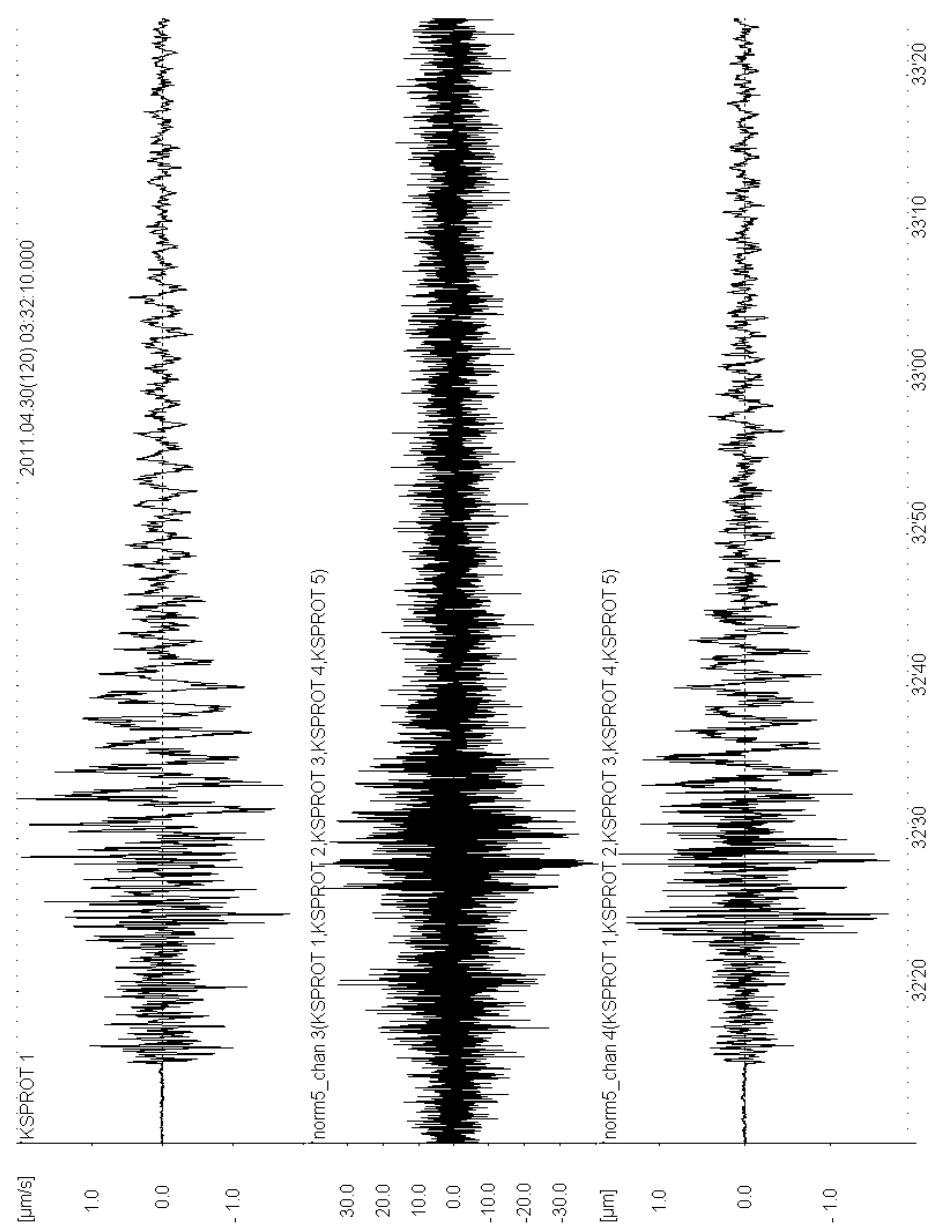

Fig. 11. The example of the seismic event traces, prepared for analysis. Upper channel channel 1, first of two from the first electromechanical rotational seismometer TAPS. Middle channel - rotational seismogram from AFORS-1, sampling-normalized to the channel 1. Lower channel - first from the second TAPS, sampling-normalized to the channel 1. The mining seismic event in LGOM (western Poland) on 2011.04.30, at 03:32 UTC 
For the analysis, we divided each signal into several frequency bands, then searched for similar - and dissimilar! - rotational motions. As it is seen in the Fig. 12, even this method did not reveal great similarity between the rotations obtained from AFORS-1 and from TAPSes. Here, the time-period when the $\mathrm{P}$ waves have arrived is shown. For all the transformations, we applied the same procedures, including the digital filters which we constructed in Matlabß.
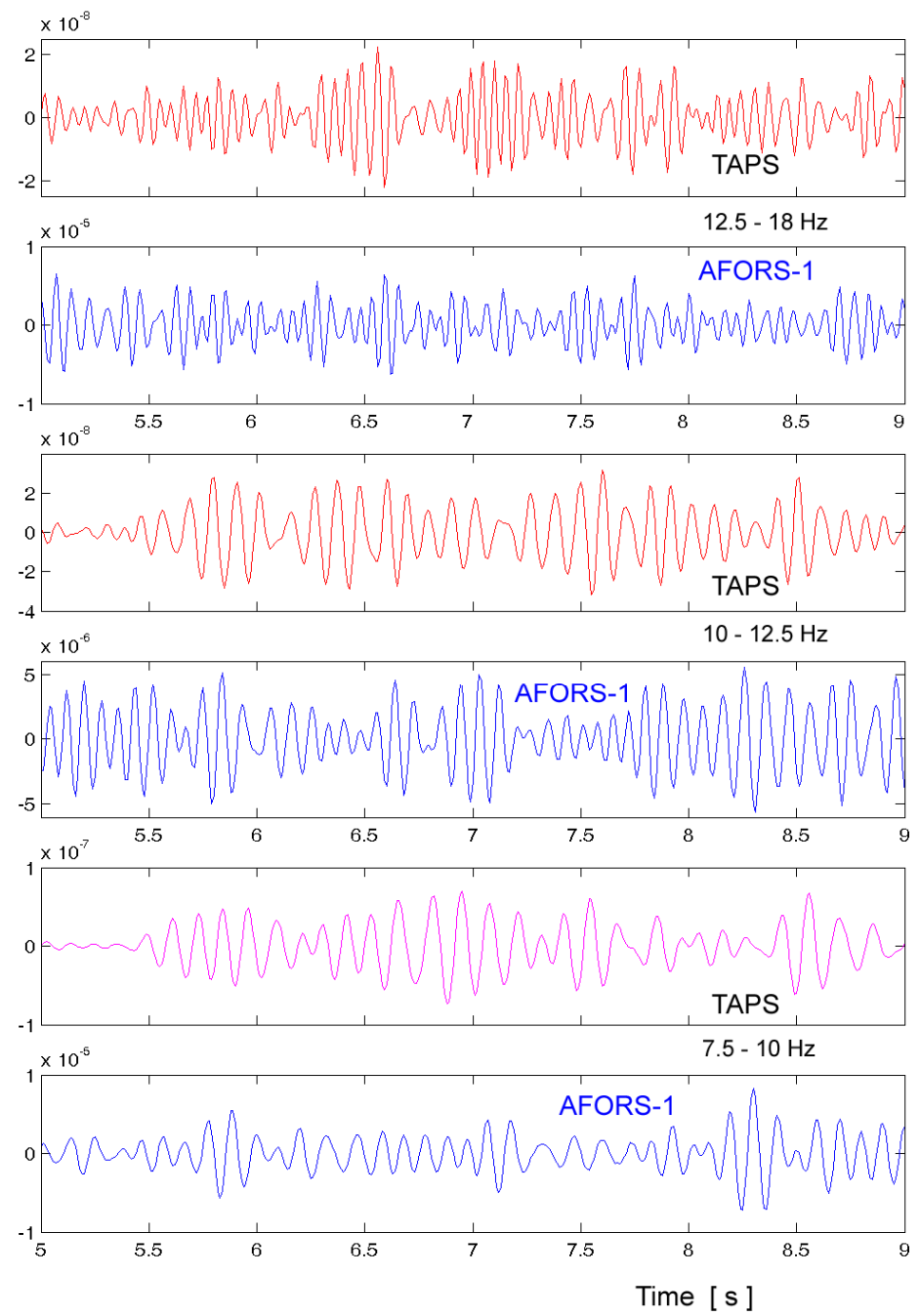

\section{LGOM 2011.04.30 03:32}

Fig. 12. Rotation motions in the recording of a mining seismic event, during $\mathrm{P}$ waves arrivals, as seen in three frequency bands: $12.5-18 \mathrm{~Hz}, 10-12.5 \mathrm{~Hz}$ and $7.5-10 \mathrm{~Hz}$. In each of the paired diagrams, the upper one shows the rotation calculated from the system of TAPSes, the lower one - the rotation sensed by the AFORS-1 
Further, we tried to compare both rotational signals after averaging each of them for consecutive time-periods of $0.5 \mathrm{~s}$, that is -50 samples. The results, for six chosen frequency bands, are shown in Figs. 13 - 16. The averages of the absolute values of rotations are plotted as thick line. Additionally, two other averages are added. The thin continuous is for acceleration (in fact - the difference between neighbouring samples) - again, the absolute values are averaged for consecutive stages. Finally, thin dashed line shows the average of the squared rotational signal. These additional plots were normalized to the rotational signals, so their maxima coincide. The Figs. 13 and 14 are obtained from the analysis of the shock from April 30th; the Figs. 15 and 16 - from the analysis of the stronger shock, that of June 28th.
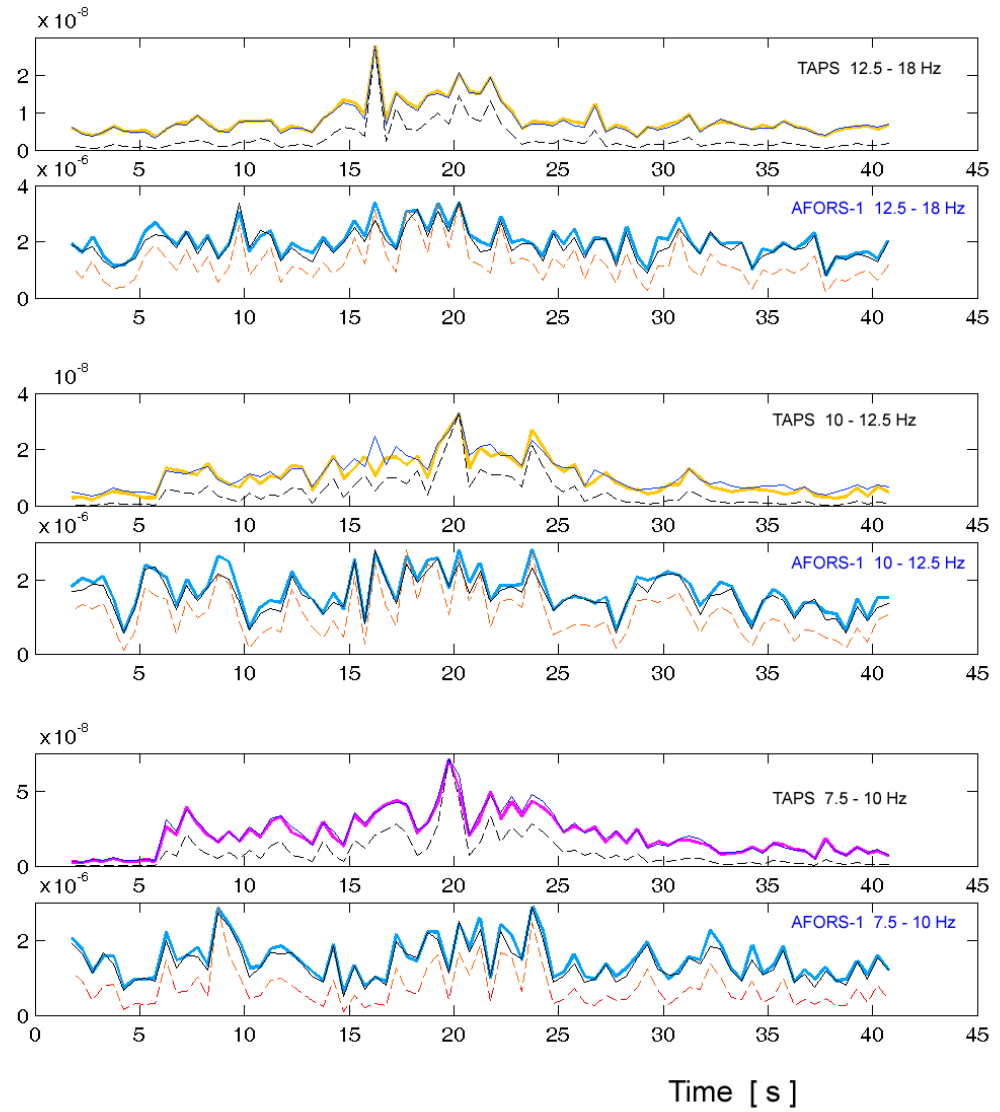

\section{LGOM 2011.04.30 03:32}

Fig. 13. The rotations, their squares and time-differentials equivalent to rotational acceleration, averaged in consecutive stages, 50 or 0.5 second long. Before averaging, the rotations and their differentials were transformed into the absolute values. The seismic event in LGOM, 2011.04.30, at 03:32 UTC. The upper frequency bands: $12.5-18 \mathrm{~Hz}, 10-12.5$ $\mathrm{Hz}$ and $7.5-10 \mathrm{~Hz}$. In each of the paired diagrams, the upper one shows signals obtained from the system of TAPSes, the lower one - from the AFORS-1 
Searching for a similarity between peaks, indentations and their sequences, placed in the same points in the both plots of rotations' average values, is the searching for hidden similarities between the rotations obtained from electromechanical seismometers system and these obtained from AFORS-1. As it is seen in the Figs. 13 - 16, only partial similarity may be found, in the specific frequency bands only. In the two cases presented here, these were the frequency bands $3-4.8 \mathrm{~Hz}$ and $10-12.5 \mathrm{~Hz}$, and to lesser extent $-12.5-18 \mathrm{~Hz}$.
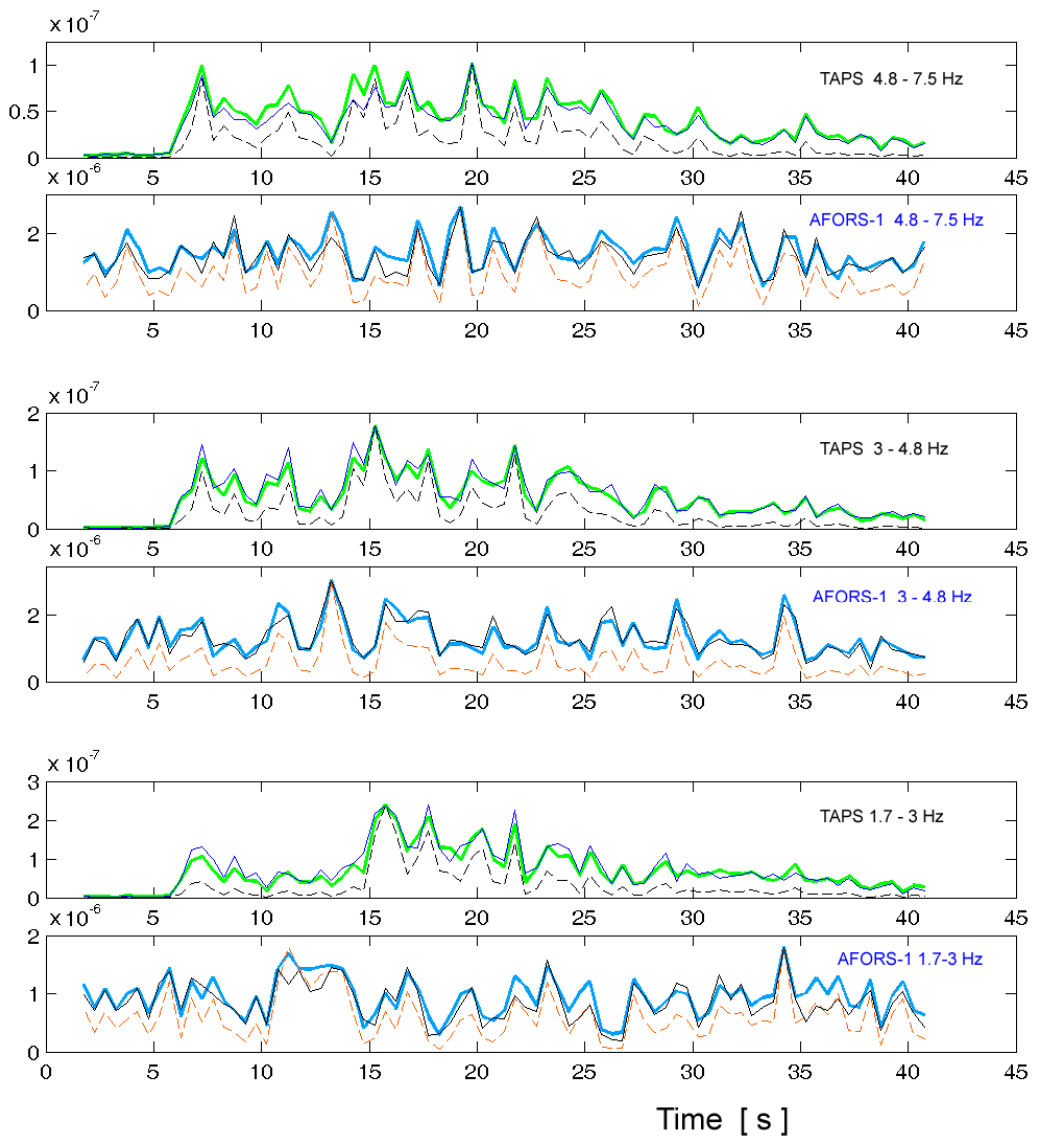

\section{LGOM 2011.04.30 03:32}

Fig. 14. Analysis as in Fig. 13; the same seismic event. The lower frequency bands: 4.8-7.5 $\mathrm{Hz}, 3-4.8 \mathrm{~Hz}$ and $1.7-3 \mathrm{~Hz}$

It is often hard to find the beginning of the seismic event's trace in the diagram of rotational motions; dividing the signals into frequency bands usually helps in the case of recordings from electromechanical seismometers (TAPSes), but for recordings from AFORS-1 the improvement is smaller. For the frequencies in the band $12.5-18 \mathrm{~Hz}$, and higher, the rotational trace of a mining seismic event is often obscured by the noise. This is more clearly seen in the readings from AFORS-1 because of a high sensitivity of this 
equipment to high frequency rotations. The mentioned noise might be of an instrumental or external origin, the latter is more probable. Nevertheless, the rotational traces of the seismic events in LGOM area also bear high frequency rotations, in various portions. These high frequency rotations may originate in the focus, or in the vicinity of the seismic station, as a response to the arriving seismic waves. We relate the latter explanation also to the short bursts of high frequency rotational motions, which quite often accompany the recording of an earthquake or other seismic event (Jaroszewicz et al., 2011b).
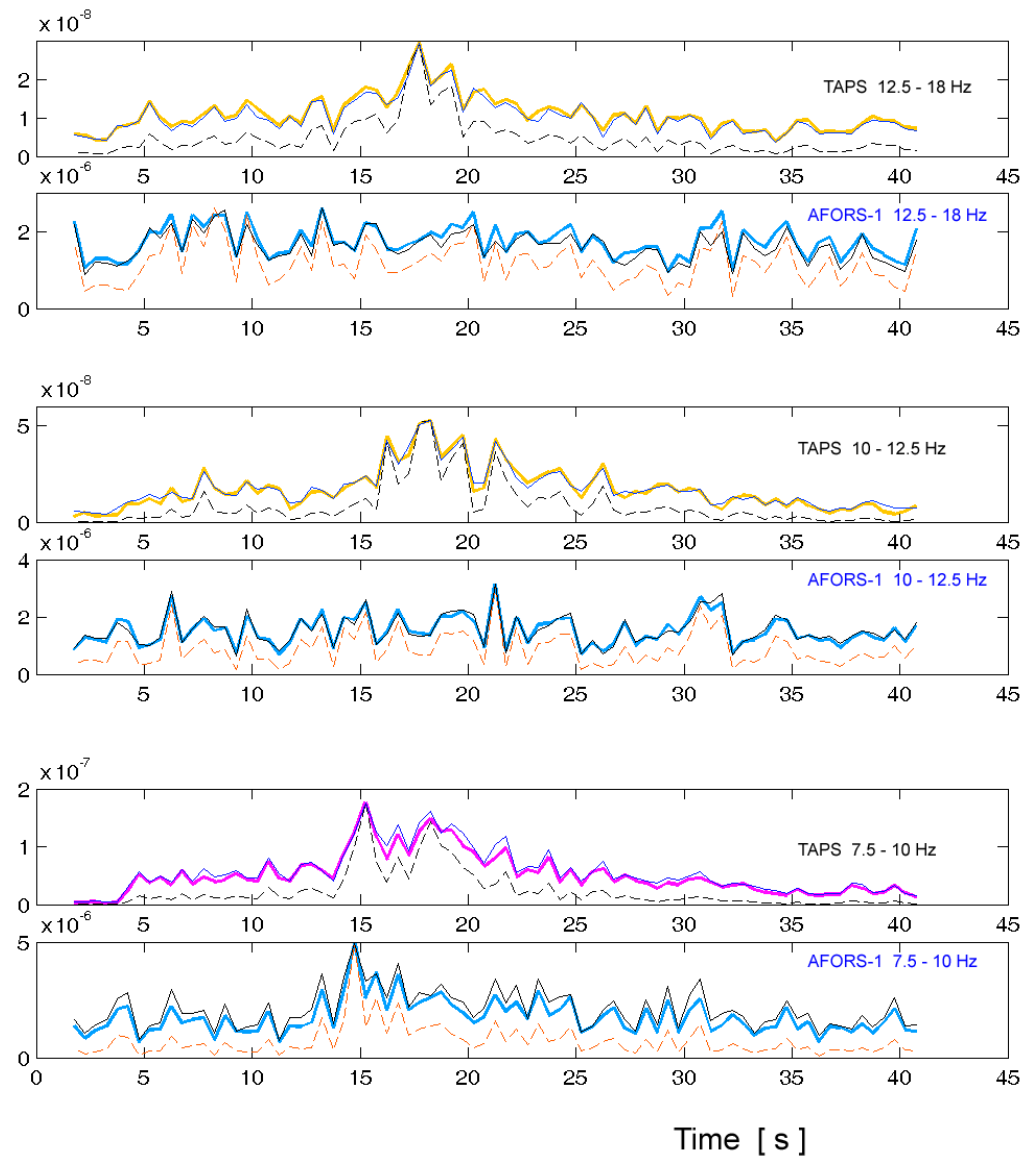

LGOM 2011.06.28 23:16

Fig. 15. Analysis as in Fig. 13. The seismic event in LGOM, 2011.06.28, at 23:16 UTC. The upper frequency bands: $12.5-18 \mathrm{~Hz}, 10-12.5 \mathrm{~Hz}$ and $7.5-10 \mathrm{~Hz}$

When a recording from AFORS- 1 is analyzed in low frequencies, below $1.7 \mathrm{~Hz}$, a trace of a seismic event is almost not visible, and it is barely discernible also in the frequency band 1.7 - $3 \mathrm{~Hz}$. That's unfortunate, as a substantial part of rotational oscillations comes in low 
frequencies. The share of low frequency rotations varies between local events, as was found for several shocks recorded in Ojców, Poland (K. P. Teisseyre, 2006) and in l'Aquila, central Italy (K. P. Teisseyre, 2007). In each of these studies, the rotational motions were derived from the set of two TAPSes, in other words - from two pairs of electromechanical horizontal seismometers.
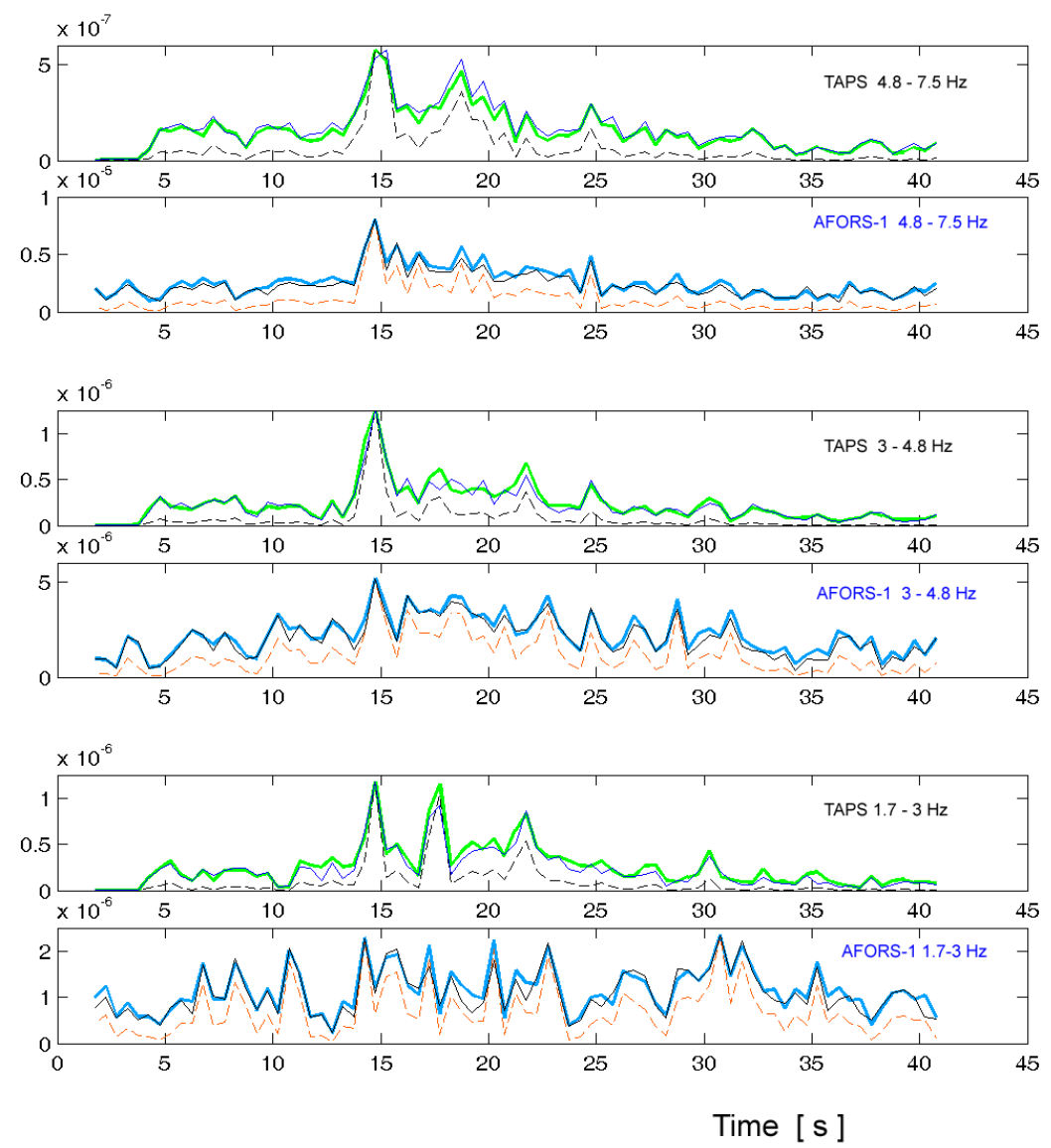

\section{LGOM 2011.06.28 23:16}

Fig. 16. Analysis as in Fig. 13. The seismic event in LGOM, 2011.06.28, at 23:16 UTC. The lower frequency bands: $4.8-7.5 \mathrm{~Hz}, 3-4.8 \mathrm{~Hz}$ and $1.7-3 \mathrm{~Hz}$

The agreement between the plots of the stage-averaged rotation and the stage-averaged squared rotation is not surprising; it shows that in the seismic energy received at the station, higher amplitudes motions are more important than the smaller ones. On the other hand, in several time-periods (stages), a disagreement between rotational acceleration and the appropriate rotational signal is often found. When the acceleration plot is below that of the adequate rotational velocity plot - see Fig. 14 - this may be explained by a shift from 
symmetry of average signal amplitudes in a relation to the zero level. But when we take into account that the acceleration has been amplitude-normalized to the rotation, it is clear that we cannot estimate the size of this shift. Such shifts may be present always, or they may be absent only in some cases and frequency bands, for example - this depicted in Fig. 15, two lowermost panels; here - the acceleration coincide with the rotation or is plotted higher except for the summit.

Some methods of cleaning the signals from possible contaminations are under development, and we are going to record rotational motions with the use of two Sagnac-type interferometers placed at some distance. Nevertheless, the studies outlined here show that the field experiments with AFORS-1 bring an important information concerning the seismic field of mining seismic events.

\section{Conclusion}

The direct measurement of the absolute rotational components with linear changes of the accuracy form $5.1 \cdot 10^{-9}$ to $5.5 \cdot 10^{-8} \mathrm{rad} / \mathrm{s}$, for the detection frequencies range from 0.83 to $106.15 \mathrm{~Hz}$ is the main advantage of the presented system AFORS. As shown in the first field test, the system type AFORS appears as the promising device to study both the seismic field generated by earthquakes at least at local distance range, and the reaction of buildings and other constructions to strong motions. In the first domain however, the whole detecting/registering system needs further studies - especially, the recordings analysed both in the low frequencies, below $3 \mathrm{~Hz}$ and in the relatively high frequencies, from $18 \mathrm{~Hz}$ upwards seem to contain too much noise. But most probably, at least part of this noise comes to the equipment from outside. Therefore, also the conditions at the Książ observatory should be checked again, despite that for other scientific equipment, as the regular seismic station KSPROT, these corridors (excavated by the slaves under German supervision during the second world war) provide the satisfactory environment.

\section{Acknowledgment}

This work was done in 2011 under the financial support of the Polish Ministry of Science and Higher Education under Key Project POIG.01.03.01-14-016/08 “New photonic materials and their advanced application" and partially the Military University of Technology statutory activity No PBS-829.

\section{References}

Arditty, H. J. \& Lefèvre, H. C. (1981). Sagnac Effect in a Fiber Gyroscope, Optic. Lett., Vol. 6, No8, (August 1981), pp. 401-403, ISSN 0146-9592

Arditty, H. J., Graindorge, Ph., Lefèvre, H. C., Martin, Ph., Morisse J. \& Simonpiétri, P. (1989). Fiber-Optic Gyroscope with All-Digital Processing, Proceedings of OFS 6/"89, Paris, Springer-Verlag Proceedings in Physics, Vol. 44, pp. 131-136

Auch, W. (1986). The Fiber-Optic Gyro - a Device for Laboratory Use Only?, SPIE Proceedings, Vol.719, pp. 28-34, ISSN 0277-786X 
Bergh, R. A., Lefèvre, H. C. \& Shaw, H. J. (1981). All-Single-Mode Fiber-Optic Gyroscope with Long-Term Stability, Optic. Lett., Vol. 6, No.10, (October 1981), pp. 502-504, ISSN 0146-9592

Burns, W. K. (1986). Phase-Error Bounds of Fiber Gyro With Polarization-Holding Fiber, J. Lightwave Tech., Vol. LT4, No.1, (January 1986), pp. 8-14, ISSN 0733-8724

Cowsik, R, Madziwa-Nussinov T., Wagoner K., Wiens D., Wysession, M. (2009). Performance Characteristics of a Rotational Seismometer for Near-Field and Engineering Applications, BSSA, Vol.99, No.2B, (May 2009), pp. 1181-1189, ISSN 0037-1106

Dai, X., Zhao, X., Cai, B., Yang, G., Zhou, K. \& Liu, C. (2002). Quantitative Analysis of the Shupe Reduction in a Fiber-Optic Sagnac Interferometer, Opt. Eng., Vol.41, No.6, (June 2002), pp. 1155-1156, ISSN 0091-3286

Droste, Z. \& Teisseyre, R. (1976). Rotational and Displacemental Components of Ground Motion as Deduced from Data of the Azimuth System of Seismograph, Publs Inst. Geophys. Pol. Acad. Sc., Vol.97, pp. 157-167, ISSN 0139-0109

Eringen, A. C. (1999). Mirocontinuum field theories. Vol. 1 Foundations and Solids, SpringerVerlag, ISNB 0-387-95275-6, New York

Ezekiel, S., Davis, J. L. \& Hellwarth, R. W. (1982). Intensity Dependent Nonreciprocal Phase Shift in a Fiberoptic Gyroscope, Springer Series in Optical Sciences, Vol.32, pp. 332336

Ferrari, G. (2006). Note on the Historical Rotation Seismographs, in: Earthquake Source Asymmetry, Structural Media and Rotation Effects, R. Teisseyre, M. Takeo \& E. Majewski, (Eds.), 367-376, ISBN 3-540-31336-2, Springer, Berlin

Franco-Anaya, R., Carr, A. J. \& Schreiber. K. U. (2008). Qualification of Fibre-Optic Gyroscopes for Civil Engineering Applications, Proc. of the New Zealand Society of Earthquake Engineering (NZSEE) Conf., (available on CD-ROM), Wairakei, New Zealand, 2008

Fredricks, R. J. \& Ulrich, R. (1984). Phase-Error Bounds of Fibre Gyro with Imperfect Polariser/Depolarizer, Electron. Lett., Vol.20, No.8, pp. 330-332, ISSN 0013-5194

Harress, F. (1912). Die geschwindigkeit des lichtes in bewegten korper, Dissertation, Jena, Germany

Harzer, P. (1914). Astron, Nachr., Vol.198, pp.377-378

Jaroszewicz, L. R. \& Krajewski Z. (2008). Application of the Fibre-Optic Rotational Seismometer in Investigation of the Seismic Rotational Waves, Opto-Electron. Rev., Vol.16, No.3, (September 2008), pp. 314-320, ISSN 1230-3402

Jaroszewicz, L. R. \& Wiszniowski J. (2008). Measurement of Short-Period Weak Rotation Signals, in: Physics of Asymmetric Continuum: Extreme and Fracture Processes, R. Teisseyre, H. Nagahama \& E. Majewski, (Eds.), pp.17-47, ISBN 978-3-540-68354-4, Springer, Berlin

Jaroszewicz, L. R., Krajewski, Z. \& Teisseyre, K. P. (2011b). Usefulness of AFORS Autonomous Fibre-Optic Rotational Seismograph for Investigation of Rotational Phenomena, Journal of Seismology, Special issue: Rotational Ground Motions, in press, ISSN 1383-4649 
Jaroszewicz, L. R., Krajewski, Z. \& Teisseyre, K. P. (2011c). The Possibility of a Continuous Monitoring of the Horizontal Buildings' Rotation by the Autonomous Fibre-Optic Rotational Seismograph AFORS Type, $6^{\text {th }}$ European Workshop on the seismic behaviour of Irregular and Complex Structures (6EWICS), Haifa, Israel, 12-13 Sept. 2011 - in press

Jaroszewicz, L. R., Krajewski, Z.\& Solarz, L. (2006). Absolute Rotation Measurement Based on the Sagnac Effect. in: Earthquake Source Asymmetry, Structural Media and Rotation Effects, R. Teisseyre, M. Takeo \& E. Majewski E. (Eds), pp.413-438, ISBN 3-54031336-2, Springer, Berlin

Jaroszewicz, L. R., Krajewski, Z., Kowalski, H., Mazur, G., Zinówko, P. \& Kowalski, J. K. (2011a). AFORS Autonomous Fibre-Optic Rotational Seismograph: Design and Application. Acta Geophys., Vol. 59, No.3, (March 2011), pp. 578-596, ISSN 00015725

Jaroszewicz, L. R., Krajewski, Z., Solarz, L., Marć, P. \& Kostrzyński T. (2003). A New Area of the Fiber-Sagnac Interferometer Aapplication, Proc. Intern. Micro-Opt. Conf. IMOC2003, Part II, Iguazu Falls, Brazil, 20-23 Sept. 2003, SBMO/IEEE (2003), pp. 661-666

Kanamori, H. (1994). Annu. Rev. Earth Planet. Sci., Vol.22, pp. 207-307

Kao, C. G. (1998). Design and Shaking Table Tests for a Four-storey Miniature Structure Built with Replaceable Plastic Hinges, Master's Thesis, University of Canterbury, Australia

Kozák, J. T. (2006). Development of Earthquake Rotational Effect Study, In: Earthquake Source Asymmetry, Structural Media and Rotation Effects, R. Teisseyre, M. Takeo \& E. Majewski, (Eds.), 3-10, ISBN 3-540-31336-2, Springer, Berlin

Krajewski, Z. (2005). Fiber-Optic Sagnac Interferometer as Device for Rotational Effect Investigation Connected with Seismic Events (in Polish). Doctor Thesis, Military University of Technology, Warsaw, Poland

Krajewski, Z., Jaroszewicz, L. R. \& Solarz, L. (2005). Optimization of Fiber-Optic Sagnac Interferometer for Detection of Rotational Seismic Events, SPIE Proceedings, Vol.5952, pp. 240-248, ISSN 0277-786X

Lee, W. H. K, Celebi, M., Todorovska, M. I. \& Igel, H. (2009). Rotational Seismology and Engineering Applications, BSSA, Vol.99, No.2B, (May 2009), ISSN 0037-1106

Lefèvre, H. C., Bettini, J. P., Vatoux, S. \& Papuchon, M. (1985a). Progress in Optical Fiber Gyroscopes Using Integrated Optics, Proceedings of AGARD-NATO, Vol. CPP-383, pp. 9A1-9A13

Lefèvre, H. C., Graindorge, Ph., Arditty, H. J., Vatoux S. \& Papuchon, M. (1985b). Double Closed-Loop Hybrid Fiber Gyroscope Using Digital Phase Ramp, Proceeding of OFS 3/'85, San Diego, OSA/IEEE, Postdeadline Paper 7

Martin, J. M. \& Winkler, J.T. (1978). Fiber-Optic Laser Gyro Signal Detection and Processing Technique, SPIE Proceedings, Vol.139, pp. 98-102, ISSN 0277-786X

McGinnis, (2004). Apparatus and method for detecting deflection of a tower, U.S. Patent application, No.0107671 A1, (10 June 2004)

Michelson, A. A. \& Gale, H. G. (1925). The Effect of the Earth's Rotation on Light Velocity," Nature, Vol.115, (18 April 1925), pp.566-566, ISSN 0028-0836 
Pogany, P. (1926). Über die Wiederholung des Harress-Sagnacschen Versuches, Ann. Physik, Vol. 385, No11, pp.217-231, ISSN 0003-3804

Post, E. J. (1967). Sagnac effect, Rev. of Modern Physics, Vo.39, No2, (April 1967), pp.475-493. ISSN 0034-6861

Sagnac, G. (1913). L'ether lumineux demontr par l'effet du vent relatif d'Etherdanus un interferometre en rotation uniforme, Compte-rendus a l'Academie des Sciences, Vol.95, pp. 708-710

Schreiber, K. U., Velikoseltsev, A., Carr, A. J. \& Franco-Anaya, R. (2009). The application fiber optic gyroscope for the measurement of rotations in structural engineering, BSSA, Vol.99, No.2B, (May 2009), pp. 1207-1214, ISSN 0037-1106

Schreiber, U., Schneider, M., Rowe, C.H., Stedman, G.E. \& W. Schlüter (2001). Aspects of Ring Lasers as Local Earth Rotation Sensors, Surveys in Geophysics, Vol.22, No.5-6, (September 2001), pp. 603-609, ISSN 0169-3298

Solarz, L., Krajewski, Z. \& Jaroszewicz, L. R. (2004). Analysis of Seismic Rotations Detected by Two Antiparallel Seismometers: Spline Function Approximation of Rotation and Displacement Velocities, Acta Geophys. Pol., Vol. 52, No.2, (June 2004), pp. 198-217, ISSN 0001-5725

Takeo, M., Ueda, H. \& Matzuzawa T. (2002). Development of Hight-Gain Rotational-Motion Seismograph, Grant 11354004, Erthquake Research Institute, Univ. of Tokyo, 5-29

Teisseyre, K. P. (2006). Mining Tremors Registered at Ojców and Książ Observatories: Rotation Field Components, Publs. Inst. Geophys. Pol. Acad. Sc., M-29 (395), pp. 77-92

Teisseyre, K. P. (2007). Analysis of a Group of Seismic Events Using Rotational Components, Acta Geophys., Vol.55, No.4, (April 2007), pp. 535-553, ISSN 0001-5725

Teisseyre, R. \& Boratyński, W. (2002), Continuum with Self-Rotation Fields: Evolution of Defect Fields and Equations of Motion, Acta Geophys., Vol.50, No.3, (March 2002), pp. 223-229, ISSN 0001-5725

Teisseyre, R. \& Gorski, M. (2009), Transport in Fracture Processes: Fragmentation of Defect Fields and Equations of Motion, Acta Geophys., Vol.57, No.5, (May 2009), pp. 583599, ISSN 0001-5725

Teisseyre, R. \& Kozák, J. T. (2003). Considerations on the Seismic Rotation Effects. Acta Geophys., Vol.51, No.3, (March 2003), pp. 243-256, ISSN 0001-5725

Teisseyre, R. (2005). Asymmetric Continuum Mechanics: Deviations from Elasticity and Symmetry, Acta Geophys., Vol.53, No.2, (February 2005), 115-126, ISSN 0001-5725

Teisseyre, R., Białecki, M. \& Górski, M. (2005). Degenerated Mechanics in a Homogeneous Continuum: Potentials for Spin and Twist, Acta Geophys., Vol.53, No.3, (March 2005), pp. 219-23. ISSN 0001-5725

Teisseyre, R., Nagahama, H. \& Majewski, E. (Eds.) (2008). Physics of Asymmetric Continuum: Extreme and Fracture Processes. Earthquake Rotation and Solition Waves, ISBN 978-3540-68354-4, Springer-Verlag, Berlin-Heidelberg

Teisseyre, R., Suchcicki, J., Teisseyre, K. P. \& Palangio, P. (2003). Seismic rotation waves: basic elements of theory and recording, Annals Geophys., Vol.46, No.4, (August 2003), pp. 671-685, ISSN 2037-416X

Teisseyre, R., Takeo, M. \& Majewski, E. (Eds.) (2006). Earthquake Source Asymmetry, Structural Media and Rotation Effects, ISBN 3-540-31336-2, Springer, Berlin 
Ulrich, R. (1980). Fiber-Optic Rotation Sensing With Low Drift, Optic. Lett., Vol. 5, No5, (May 1980), pp. 173-175, ISSN 0146-9592

Vali, V. \& Shorthill, R. W. (1976). Fiber Ring Interferometer, Appl. Optics, Vol.15, No5, (May 1976), pp.1099-1100, ISSN 0733-8724 


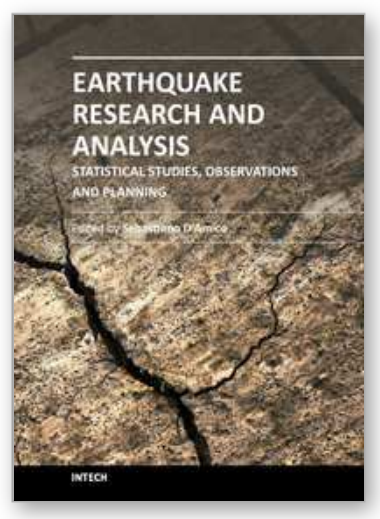

\author{
Earthquake Research and Analysis - Statistical Studies, \\ Observations and Planning \\ Edited by Dr Sebastiano D'Amico
}

ISBN 978-953-51-0134-5

Hard cover, 460 pages

Publisher InTech

Published online 02, March, 2012

Published in print edition March, 2012

The study of earthquakes plays a key role in order to minimize human and material losses when they inevitably occur. Chapters in this book will be devoted to various aspects of earthquake research and analysis. The different sections present in the book span from statistical seismology studies, the latest techniques and advances on earthquake precursors and forecasting, as well as, new methods for early detection, data acquisition and interpretation. The topics are tackled from theoretical advances to practical applications.

\title{
How to reference
}

In order to correctly reference this scholarly work, feel free to copy and paste the following:

Leszek R. Jaroszewicz, Zbigniew Krajewski and Krzysztof P. Teisseyre (2012). Fibre-Optic Sagnac Interferometer as Seismograph for Direct Monitoring of Rotational Events, Earthquake Research and Analysis - Statistical Studies, Observations and Planning, Dr Sebastiano D'Amico (Ed.), ISBN: 978-953-51-0134-5, InTech, Available from: http://www.intechopen.com/books/earthquake-research-and-analysis-statisticalstudies-observations-and-planning/fibre-optic-sagnac-interferometer-as-the-seismograph-for-directmonitoring-of-the-rotational-phenome

\section{INTECH}

open science | open minds

\section{InTech Europe}

University Campus STeP Ri Slavka Krautzeka 83/A 51000 Rijeka, Croatia Phone: +385 (51) 770447 Fax: +385 (51) 686166 www.intechopen.com

\section{InTech China}

Unit 405, Office Block, Hotel Equatorial Shanghai No.65, Yan An Road (West), Shanghai, 200040, China 中国上海市延安西路65号上海国际贵都大饭店办公楼405单元 Phone: +86-21-62489820

Fax: +86-21-62489821 
(C) 2012 The Author(s). Licensee IntechOpen. This is an open access article distributed under the terms of the Creative Commons Attribution 3.0 License, which permits unrestricted use, distribution, and reproduction in any medium, provided the original work is properly cited. 